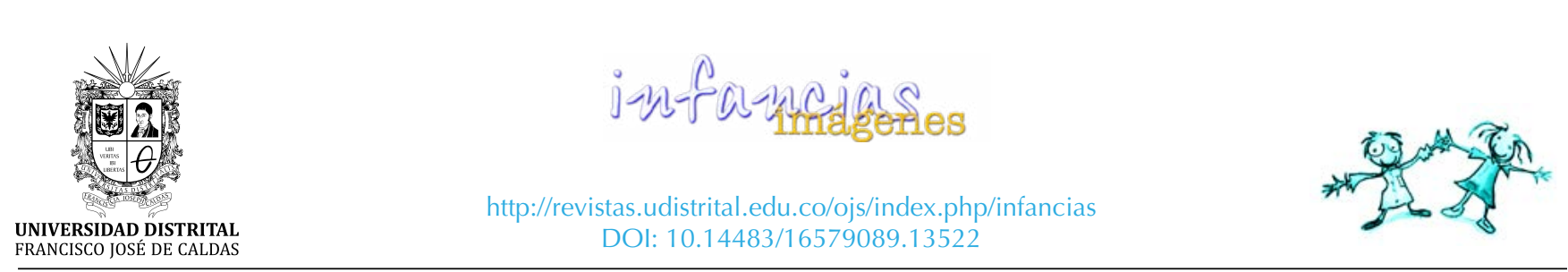

TEXTOS Y CONTEXTOS

\title{
Reconciliarnos: una manifestación de ciudadanía para propiciar desde la escuela*
}

\section{Reconciliation: a manifestation of citizenship to promote from school}

\author{
Fabio Enrique Barragán Santos¹, Agustín David Arias Rey²
}

Para citar este artículo: Barragán, F. B.; Arias, A. D. (2018).

Recibido: 25-junio-2018 / Aprobado: 16-noviembre-2018

Reconciliarnos: una manifestación de ciudadanía para pro-

piciar desde la escuela. Infancias Imágenes, 18(1), 95-104

\section{Resumen}

El programa de investigación "Ciudadanía desde el aula" ha propuesto a la reconciliación como una de 16 manifestaciones de ciudadanía que pueden propiciarse desde las prácticas de aula con el fin de desarrollar competencias ciudadanas. Este artículo profundiza en la reconciliación como manifestación de ciudadanía. Primero, se hacen distinciones entre perdón y reconciliación. Luego, se presenta la reconciliación como manifestación de ciudadanía. Enseguida, se describen cuatro competencias ciudadanas asociadas: expresión asertiva, escucha activa y positiva, memoria personal y colectiva y resiliencia. Estas competencias ciudadanas y la reconciliación misma se estudian desde un vector narrativo que hace énfasis en la importancia de los relatos en la construcción social e individual. Finalmente, se presentan consideraciones y propuestas haciendo énfasis en educar para la reconciliación desde el aula y la escuela.

Palabras clave: reconciliación, pedagogía, competencias, educación ciudadana.

\begin{abstract}
Alostract
The research program "Citizenship from the classroom" has proposed reconciliation as one of 16 manifestations of citizenship that can be promote through classroom practices in order to develop citizenship skills. This paper delves into reconciliation as a manifestation of citizenship. First, distinctions are made between forgiveness and reconciliation. Then, reconciliation is presented as a manifestation of citizenship. Next, four associated citizenship skills are described: assertive expression, active and positive listening, personal and collective memory and resilience. These citizenship skills and reconciliation itself, are studied from a narrative vector which emphasizes the importance of stories in social and individual construction. Finally, considerations and proposals are presented with an emphasis on educating for reconciliation from both the classroom and the school.
\end{abstract}

Keywords: reconciliation, pedagogy, skills, citizenship education.

\footnotetext{
* Artículo derivado del programa de investigación Ciudadanía desde el Aula, desarrollado entre marzo de 2015 y marzo de 2018 , con financiación de Colciencias y Unisangil. Para más información véase www.ciudadaniadesdeelaula.com

1 Magíster en Pedagogía e Investigación en el Aula. Licenciado en Administración Educativa. Director del Grupo de Investigación TAREPE, Unisangil. Autor de obras literarias. Correo electrónico: fbarragan@unisangil.edu.co

2 Psicólogo. Consultor en orientación profesional. Miembro del Grupo de Investigación TAREPE, Unisangil. Correo electrónico: agustindavid.
} ariasrey@gmail.com 


\section{Introducción}

La construcción de ciudadanía en tiempos de posconflicto representa numerosos desafíos; uno de los cuales indudablemente atañe a la reconciliación. En sociedades como la colombiana, atrapadas durante decenios en un ciclo de violencia crónica, el reto de reparar y reconstruir el tejido social desgarrado por acciones de unos y otros pasa necesariamente por dos procesos que están ligados pero que guardan sus particularidades: el perdón y la reconciliación.

Los dos términos (perdón y reconciliación) son conocidos y pronunciados con frecuencia. Sin embargo, ¿están claras las diferencias entre uno y otro?, ¿sabemos cómo llevarlos a la práctica y cómo educar para propiciar su realización?

Este texto surge de la experiencia y la reflexión acumuladas por los autores en procesos de investigación, especialmente en el programa "Ciudadanía desde el aula", en los que han visto la necesidad de diferenciar entre perdón y reconciliación, aprender a practicarlos y educar para que cada vez sean más posibles.

Se empieza por una distinción entre perdón y reconciliación, enfatizando paulatinamente en la segunda. Posteriormente, se incursiona en la propuesta del programa "Ciudadanía desde el aula": la reconciliación como una manifestación de ciudadanía que propicia y requiere un conjunto de competencias ciudadanas. Luego se profundiza en cuatro de ellas: expresión asertiva, escucha activa y positiva, memoria personal y colectiva y resiliencia. Finalmente, se ofrecen algunas consideraciones y sugerencias sobre lo que puede hacerse desde el aula para propiciar la reconciliación.

\section{Distinciones entre perdón y reconciliación}

La reconciliación supone la aceptación mutua entre adversarios, la voluntad mutua del encuentro entre víctimas y perpetradores con miras a una futura convivencia; a diferencia del perdón. En este sentido, si bien el perdón, como superación de emociones negativas como el odio, el deseo de venganza o el resentimiento, se constituye en un proceso que favorece y propicia la reconciliación, no necesariamente desemboca en esta (Cortés, Torres, López-López, Pérez y Pineda-Marín, 2016; López, 2013).

El perdón sin reconciliación ocurre, de acuerdo con Palanski (2012), cuando la víctima desea liberarse de los efectos negativos que para sí misma tienen sentimientos como el afán de venganza y la hostilidad, mas no con la intención de restaurar la relación. La víctima, al anticipar los costos que implica restablecer y permanecer en la relación, concluye que estos son más grandes que los beneficios. Ya no es rehén de sentimientos negativos en relación con el agresor, mas no requiere ni desea restaurar la relación, pues lo primero resulta benéfico en términos emocionales, lo segundo no.

Lo crucial de la reconciliación es su carácter recíproco, la transformación de la interacción entre quienes han estado involucrados en espirales de dolor. Quienes han vivido abatidos por la fatalidad impuesta y quienes han participado en dicha imposición comparten la idea de que restaurar la relación es deseable. Se trata de transitar desde un pasado en conflicto hacia un futuro compartido, como lo propone la Unidad para la Atención y Reparación Integral a las Víctimas (s. f.). En este orden de ideas, se asume que el proceso de reconciliación es deseable para ambas partes y no solo para quien ha sido receptor del daño. Según Brouneuos consiste en el "reconocimiento mutuo del sufrimiento pasado y el cambio de actitudes y comportamientos destructivos por relaciones constructivas para una paz sostenible" (como se cita en Ugarriza, 2013, p. 150). Similar aproximación hacen Bocanegra, González y Olaya (2016) al subrayar como categoría central de la reconciliación la formación de relaciones pacíficas basadas en la confianza, la aceptación y la cooperación.

Es claro que este reconocimiento mutuo, esta formación de relaciones pacíficas, ha de establecerse ante todo (pero no exclusivamente) entre quienes han estado cubiertos por dinámicas de destrucción de la convivencia: bien sea recibiendo los agravios o generándolos, o (lo más probable en sociedades como la colombiana tras decenios de conflicto armado) participando de manera complementaria en una escalada de enfrentamiento en la cual el 
padecimiento mutuo es la constante; suspendidos en un péndulo de degradación alejado cada vez más del centro, de la dignidad humana.

Es largo y complejo el proceso de reconciliación, en el cual víctimas y victimarios restauran relaciones o las construyen basados en la confianza y la cooperación. Proceso que se enmarca siguiendo los lineamientos de la Unidad para la Atención y Reparación Integral a las Víctimas (s. f.), en lo que puede denominarse reconciliación interpersonal. Este proceso no solo es entre víctimas y victimarios, sino en general entre ciudadanos que tuvieron desacuerdos y enfrentamientos. Además de este proceso de reconciliación interpersonal, la entidad añade y distingue dos categorías de reconciliación, que para el momento histórico que vive Colombia son indispensables: la reconciliación social y la reconciliación política.

De este modo, la reconciliación alude al restablecimiento de relaciones entre individuos o comunidades que han estado enfrentadas, pero no se agota allí. Se requiere, en sociedades como la colombiana que transitan hacia el posconflicto, poner en marcha procesos que tengan en cuenta a toda la sociedad. Como lo sostiene Bueno: “Un proceso de reconciliación conlleva desde un sentido de cambio más personal (ya sea a escala ética o religiosa) a uno interpersonal, cultural, político, social y hasta económico" (2006, p. 67).

Los aportes de Bueno (2006) permiten pensar que no es corriendo por una sola vía como ha de comprenderse la reconciliación. Mejor resulta verla como un cruce de caminos en el que, además de la restitución de la relación entre víctima y victimario, se transita por las sendas de nuevos consensos sociales incluyentes, basados en el respeto a los derechos humanos y el entendimiento entre culturas atravesadas por la intolerancia. Sendas de reconstrucción de relaciones vecinales, familiares o comunitarias previamente fracturadas. Rutas de reconocimiento de los propios errores y aceptación del otro. Tránsito por la reparación psicosocial de las víctimas y la consecuente restitución de su integridad.

El Estado es un actor directo en los procesos de reconciliación (Bueno, 2006) y forma parte activa de estos al lado de las víctimas y los victimarios.
Garantizar la aplicación de la justicia así como la reparación de las víctimas y la sociedad, en tiempos de posconflicto, es una función que le corresponde y que, de no darse, bloquea o aplaza ostensiblemente cualquier proceso efectivo y sostenible de reconciliación.

Una cartografía útil para entender los procesos de reconciliación consiste en reconocer los tres niveles de complejidad ya mencionados: reconciliación interpersonal, reconciliación social y reconciliación política. Este texto reconoce la importancia de esta clasificación entre diferentes modos de reconciliación, sin entenderlos como procesos separados en la vida de las personas sino como distinciones conceptuales que favorecen mayor comprensión, pero que también pueden verse en muchas situaciones como procesos separados, dado que existen situaciones en ámbitos laborales, escolares y familiares en las que la ocurrencia de agravios se restringe a dichos ámbitos sin traspasar la membrana hacia otros escenarios (sociales y políticos).

Ahora bien, se ha señalado que la reconciliación interpersonal se evidencia cuando a través de un esfuerzo personal y colectivo los que han sido adversarios, oponentes o enemigos se atreven a compartir un mismo espacio de convivencia. Construcción mutua que obedece, en parte, al deseo de víctimas y perpetradores de satisfacer ciertas necesidades emocionales que han quedado deterioradas tras los episodios de conflicto. Así lo sugieren Shnabel y Nadler (2008), quienes entienden la reconciliación como un intercambio social en el que víctima y perpetrador buscan restaurar necesidades emocionales que han quedado deterioradas tras los sucesos de conflicto. Mientras la víctima busca empoderamiento (tras experimentar sentimientos de inferioridad en relación con su autoestima, su percepción de control y su honor) el perpetrador persigue aceptación por parte de la comunidad tras experimentar ansiedad en torno a la exclusión social causada por el señalamiento de violar las normas morales de la comunidad. Así, la víctima busca recuperar su poder y el perpetrador su imagen moral.

Este intercambio social requiere actos de parte y parte. La víctima espera del perpetrador el 
reconocimiento de responsabilidades y la petición de perdón como camino hacia el empoderamiento. Entre tanto el perpetrador espera empatía por parte de la víctima en relación con su situación (miedo al rechazo social) e incluso comprensión en torno a las circunstancias que le compelieron a Ilevar a cabo actos socialmente inaceptables ${ }^{3}$. Esta comprensión no exime de responsabilidad al victimario; pero quizá puede desplazar la mirada de la culpa exclusiva del perpetrador hacia una perspectiva más amplia que reconozca contextos sociales y políticos. En esta línea se mueve Palanski (2012), quien sostiene, apoyado en estudios previos, que la reconciliación es más probable si una víctima coloca parte de la culpa por un delito en otro lugar que no sea el perpetrador.

¿Cómo avanzar hacia estos actos de comprensión tras vivir la barbarie? Pero también ¿cómo emprender caminos de reconciliación si se mantienen sentimientos de venganza y aniquilación hacia el otro? La reconciliación exige determinadas actitu-

des, conocimientos y capacidades (competencias) que se pueden propiciar a través de una pedagogía especialmente intencionada.

\section{La reconciliación como manifestación de ciudadanía}

"Ciudadanía desde el aula" es un programa de investigación pedagógica que tiene por objetivo general desarrollar estrategias y orientaciones didácticas para educar en competencias ciudadanas en establecimientos educativos de la provincia de Guanentá4.

Componentes esenciales del enfoque pedagógico de este programa son las competencias ciudadanas y las manifestaciones de ciudadanía que el programa adoptó. En cuanto a competencias ciudadanas, se acogió el concepto del Ministerio de Educación Nacional (MEN): "son el conjunto de conocimientos y de habilidades cognitivas, emocionales y comunicativas que, articulados entre sí, hacen

3 Llama la atención aquí el papel de la empatía con el perpetrador. Esta distinción otorga un valor conceptual a la empatía pues una mirada simplista ubicaría únicamente a la víctima como depositaria. Postular empatía con el perpetrador es un salto cualitativo de esta competencia.

4 La provincia de Guanentá está integrada por 18 municipios del Departamento de Santander, en Colombia. posible que el ciudadano actúe de manera constructiva en la sociedad democrática" (2004, p. 8).

Las manifestaciones de ciudadanía son una denominación aportada por el programa y se han definido como "situaciones sociales en las cuales se evidencian competencias ciudadanas de una o varias personas" (Barragán y Arias, 2018). Por ejemplo: debatir es una situación en la que se evidencian: manejo de emociones, expresión asertiva, escucha activa y positiva, argumentación y consideración de diversas perspectivas, entre otras competencias. Por esta razón, debatir forma parte de las 16 manifestaciones de ciudadanía que el programa promueve, al lado de reconciliarse, deliberar, regular el poder, indignarse y otras más.

La propuesta de "Ciudadanía desde el aula" también incluye un conjunto de 15 competencias ciudadanas (Barragán y Arias, 2018). El punto de partida son los lineamientos del MEN, además, se incluyen otras competencias que docentes e investigadores consideraron pertinentes para el ejercicio y la construcción de la ciudadanía.

Si bien todas las competencias ciudadanas pueden aportar a las manifestaciones de ciudadanía, cabe mencionar en este caso algunas que guardan estrecha relación con la reconciliación: resiliencia, expresión asertiva, memoria personal y colectiva, manejo de emociones, empatía, confianza, consideración de diversas perspectivas y escucha activa y positiva (figura 1).

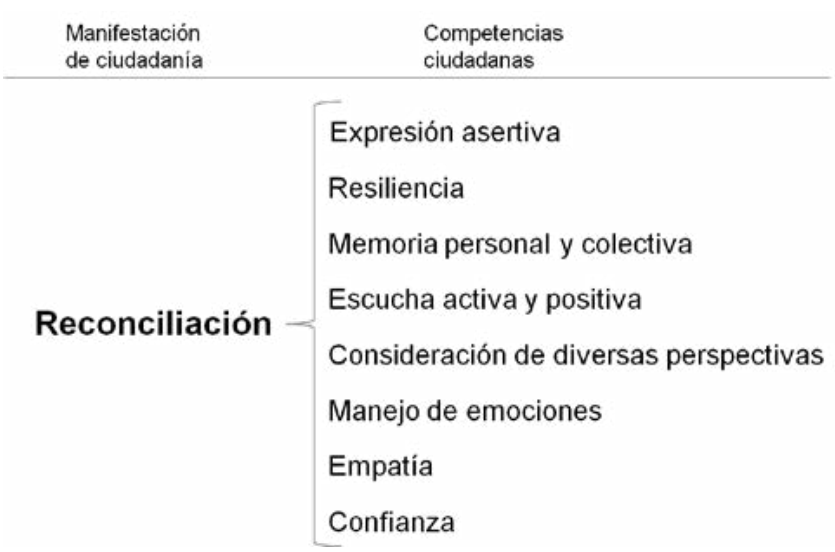

Figura 1. Principales competencias ciudadanas asociadas a la reconciliación

Fuente: elaboración propia. 
A continuación, se hará énfasis en cuatro competencias cardinales para que la reconciliación sea posible. Aunque todas las competencias ciudadanas son importantes, por cuestiones de extensión se profundiza solo en estas cuatro, que pueden considerarse cardinales en el actual momento histórico colombiano.

\section{Expresión asertiva y escucha activa y positiva}

Quienes han soportado la humillación y el sufrimiento deben realizar un gran esfuerzo para controlar prejuicios y emociones cuando escuchan a otros que defienden o justifican a los causantes de su dolor, o cuando escuchan a sus propios verdugos exponiendo su verdad. Las víctimas, con toda razón, suelen defender de modo fehaciente su versión de los hechos y reclamar justicia. Sin embargo, si cada una de las partes considera su relato de los hechos como la única verdad, se bloquea la reconciliación.

En palabras de Bueno:

No se trata de llegar a una única verdad, se trata de escuchar las múltiples verdades de los actores, las cuales son fragmentadas, relativas, pero igualmente válidas [...] Escuchar al otro contribuye a relativizar el propio sufrimiento, a encontrarle sentido en un contexto social y político determinado y así desvirtuar la venganza. (2006, p. 74)

Las Escuelas de Perdón y Reconciliación (ES. PE. RE) han comprendido este desafío y realizan procesos pedagógicos en los cuales "las versiones oficiales de los acontecimientos individuales y colectivos son reconstruidas en la perspectiva del reencuentro, la verdad, la justicia y la reparación" (Fundación para la Reconciliación, s. f.).

Esta reconstrucción discursiva necesita en primera instancia de la expresión asertiva, como una competencia ciudadana que consiste básicamente en la expresión de las ideas y emociones propias cuidadosamente, constructivamente (Chaux, 2012). La expresión asertiva sirve para que todas las partes se expresen, le hagan saber a los otros cómo se sintieron, qué recuerdan, qué consecuencias les acarrearon los hechos, observando, monitoreando y revisando los tonos y las emocionalidades que aguzan las agresiones y el odio.

Además, para reconstruir los relatos hace falta una competencia que en "Ciudadanía desde el aula" se ha denominado escucha activa y positiva, la cual se ha entendido como una disposición a escuchar al otro sin prejuicios, con actitud comprensiva y haciéndole saber que se le escucha. Es necesario diferenciar entre escuchar y "dejar hablar". Se puede permitir que las víctimas narren su relato sin escucharlas, se puede dejar hablar a los victimarios sin escucharlos. Es común asistir a foros y debates en los que cada quien solo espera su momento para hablar sin prestarles atención a las palabras de los demás, sin esforzarse por comprenderlos.

La reconciliación exige una verdadera disposición cognitiva y emocional para escuchar los relatos de los otros, aunque no estemos de acuerdo con su versión. Comprender el relato del otro no significa estar de acuerdo con él. La expresión asertiva y la escucha activa y positiva se complementan para hacer posible la comunicación y cultivar en terreno fértil la reconciliación.

\section{Memoria personal y colectiva}

Relativizar el propio sufrimiento no es desconocer el pasado, ni decretar el olvido. No es una concesión de silencios que se otorga a la historia. Al contrario, la memoria se constituye en elemento inherente de la reconciliación. La manera como las personas o comunidades involucradas en tramas sociales caracterizadas por el daño, la agresión y el conflicto, se relacionan con su pasado es crucial en este sentido.

¿De qué memoria estamos hablando? ¿Una copia fiel del pasado o un proceso de reorganización que el sujeto realiza a partir de la experiencia vivida?

Asumir la primera postura implica que ante un mismo hecho todos lo recuerdan de la misma manera, sin aportar interpretaciones y significados respecto a lo ocurrido. La segunda forma (entender la memoria como un proceso de reorganización) supone que si bien hay hechos concretos que inciden sobre la biografía del sujeto, este otorga significado 
a dichos hechos. Se habla en este caso de la memoria como un proceso narrativo y no simplemente como un acto de réplica del pasado ${ }^{5}$.

En las ciencias sociales ha cobrado fuerza el enfoque narrativo, que da importancia al significado que las personas hacen de las experiencias vividas. La unidad de análisis no son tanto los hechos sino los relatos o narraciones que el sujeto construye. Según esta propuesta "se puede definir la narración como una unidad de significado que brinda un marco para la experiencia vivida" (Epston, White y Murray, 1996, p. 122).

Entender y pensar la memoria como relato y no como réplica traza un camino propicio para la reconciliación: conduce a una relación distinta con el pasado, en la cual no prima el monopolio de relatos basados en el rencor, el odio o la impotencia ante la agresión.

El Observatorio para la paz, en Colombia, ha desarrollado una experiencia con "mujeres que han vivido la fuerza de la guerra y que han tomado la decisión de tejer colectivamente nuevos caminos de vida, sin olvidar su pasado, pero sí trascendiendo amorosamente sus historias de violencia" (Observatorio para la paz, s. f.). Este es un ejemplo de la memoria como competencia ciudadana que favorece la reconciliación.

Se trata de una comprensión de la memoria como proceso narrativo que, lejos de tergiversar el pasado o negarlo (especialmente en situaciones adversas y traumáticas), abre la posibilidad de relatos diferentes al dominante, permitiendo transitar más pronto hacia un proceso de reconciliación en el que las personas involucradas puedan referirse al pasado desde otra perspectiva. En lugar de recordar para perpetuar agravios, con palabras como: "Vengaremos el horror vivido. Es necesario destruirlos para honrar a los nuestros, así padezcamos los golpes de la destrucción", se puede recordar

5 "La hipótesis explicativa más extendida entre aquellos que investigan el papel de la memoria, es que mientras leemos, mientras observamos lo que sucede a nuestro alrededor o mientras nos cuentan una historia construimos significados e inferencias y son esos significados e inferencias los que almacenamos en nuestra memoria" (Ruiz-Vargas, 1997, p. 126). "El pensamiento contemporáneo ha desmontado la ingenua creencia de que el pasado tal cual fue, el pasado en sí, es recuperable. La memoria, como ya se dijo, no es un almacén ni un inventario; es una facultad que conserva, pero que elabora, es una memoria creativa" (Fernández, 1997, p. 71). para imaginar posibilidades, por ejemplo, con frases como: "Jamás olvidaremos el estruendo del horror, los gritos atravesando el silencio de la noche; jamás dejaremos sepultados, bajo los escombros de la amnesia, el Ilanto, la desolación vivida, pero nos merecemos la esperanza".

Difícilmente se avanzará hacia procesos de reconciliación en Colombia si tras vivir una situación adversa, dolorosa, agobiante, traumática (la masacre, el desplazamiento, la tortura, la desaparición forzada, el secuestro, la fragmentación de la familia o la penuria económica, por ejemplo) las víctimas y la sociedad en general reconstruyen su pasado únicamente a través de un relato dominante basado en las heridas ocasionadas. Si la cultura que rodea al herido se empecina en reeditar los mismos relatos de odio y venganza contra el agresor se gesta una violencia cultural ${ }^{6}$.

Es necesario que las instituciones sociales que acompañan a la víctima permitan la emergencia de nuevos relatos en los que no solo se exprese impotencia, también heroísmo; no solo se realce el horror del oprobio, además la solidaridad de la comunidad; no solo haya ausencia de autoridad, también presencia de grupos de apoyo.

Una pedagogía para la reconciliación en Colombia debe preguntarse sobre la manera como presenta y trata la historia; es decir, la manera como construye memoria. Por ejemplo, es necesario exaltar el heroísmo de las madres que se resistieron a que sus hijos formasen parte de la guerra, y de quienes sobrevivieron y salieron adelante sin tomar las armas. Mientras los únicos héroes que se exalten en la escuela sean los próceres y mártires que mataron y se hicieron matar se estará gestionando una memoria estéril para procesos de reconciliación.

\section{Resiliencia}

Si entendemos la resiliencia como la capacidad humana para resistir en las tribulaciones, lidiar con las adversidades y construir desde el dolor (Arias, 2010), podemos inferir que la reconciliación y la resiliencia comparten vasos comunicantes.

6 "La violencia cultural son aquellos aspectos de la cultura, materializados por medio de la religión y la ideología, el lenguaje y el arte, y las ciencias en sus diversas manifestaciones, que justifican o legitiman la violencia directa o la estructural" (Galtung, citado por Hueso, 2000, p. 130). 
Resiliencia cuyo tejido requiere, entre otros, del hilo narrativo de la memoria en los términos que se han expuesto. Cyrulnik, uno de los exponentes y estudiosos de este fenómeno sostiene:

Más elaborados y menos estereotipados que los discursos, los relatos exigen una reorganización de los hechos inscritos en la memoria, una reorganización realizada con la intención de construir una representación de uno mismo dirigida a quienes tenemos cerca, a la cultura o a una tercera persona real o imaginaria [...] mientras sea posible modificar la imagen que nos hacemos de nosotros mismos, mientras una intervención en la realidad psíquica y social nos permita trabajar en ella, la resiliencia será posible, puesto que consiste, simplemente en reanudar, tras una agonía psíquica, un determinado tipo de desarrollo. (2005, p. 38)

Los sujetos o las comunidades que han pasado por acontecimientos infaustos y están desplegando conductas de reconciliación, son sujetos y comunidades resilientes. $\mathrm{O}$, dicho al revés, la resiliencia se convierte en competencia necesaria para la emergencia de la reconciliación, pues por definición quien es resiliente lo es no solo por su resistencia ante la fatalidad, sino por su capacidad para construir desde el dolor. Construcción que toma fuerza y coraje en la reconstrucción del tejido social al lado de quienes fueron considerados como enemigos, victimarios o adversarios.

Acercarse al fenómeno desde una perspectiva sistémica que tiene en cuenta tanto al sujeto como al medio que lo rodea es más congruente y coherente con el concepto. En este sentido, es más apropiado hablar de trayectoria resiliente (como un proceso) y no tan solo de resiliencia (como un producto).

Acogiendo de nuevo los aportes de Cyrunik, la trayectoria resiliente depende por lo menos de tres factores: a) la estructura del acontecimiento adverso (¿catástrofe natural o saña personal?, ¿abandono o desplazamiento?, ¿enfermedad biológica o discapacidad ocasionada?, etc.); b) el desarrollo y la historia del sujeto previos a la tragedia; y c) la organización del apoyo después del acontecimiento, pues "puede impulsar un proceso de resiliencia o bloquearlo" (2009, p. 49).
La posibilidad de emprender un camino resiliente se desdibuja si los discursos culturales predominantes se empecinan en hacer eco de retahílas que promueven la degradación del otro y la visión maniquea del conflicto; si las instituciones sociales que acompañan al golpeado lo someten a un proceso de revictimización, o de resignación, o de mayor desesperación (los paseos burocráticos, la cárcel de la espera, la aridez de negligencia, el golpe seco de la indiferencia); si la comunidad que podría sostener a los agobiados está igualmente resquebrajada o permanece indiferente ante su agonía.

En definitiva, la resiliencia es un proceso que se apuntala en gran parte sobre las redes socioculturales que se tejen alrededor de los conmocionados por la adversidad. Y parte de estas redes socioculturales la conforman los relatos erigidos en torno a lo acaecido. Relatos socioculturales que inciden sobre la manera como los sujetos y las comunidades hacen uso de su memoria. Retornando a las palabras de Cyrulnik:

Los autores de relatos (los periodistas, novelistas, cineastas o ensayistas) habitualmente proporcionan tres tipos de retórica para hablar de un mismo hecho real: Un discurso placebo que adormece a todos: "No es tan grave, ya pasará; hay que superarlo y continuar viviendo".

Un discurso nocebo que enloquece a todos: "Ya no hay solución posible. [...] Vamos a morir y por culpa de $[\ldots]^{\prime \prime}$

Un discurso explicativo, interactivo, que promueve los encuentros y provee de consignas que contribuyen a dominar la situación. Tiempo después los afectados reflexionarán sobre él o utilizarán ese relato para reorganizar la representación y agregarle un compromiso físico y afectivo.

Sólo entonces es posible realizar el trabajo de resiliencia. (2009, p. 79)

\section{Consideraciones pedagógicas}

El paradigma pedagógico de las competencias ciudadanas deja claro que no basta con un saber teórico sobre los conceptos relacionados con la ciudadanía, sino que se requiere de la práctica cotidiana, que genere hábitos y un aprendizaje 
significativo (Chaux, 2012). Es necesario que la escuela se vuelva un lugar en el que sea posible vivir la reconciliación, y la ciudadanía en general (Mockus, 2004; Toro y Tallone, 2011; Camps, 2011; Barragán, Arias y Barragán, 2018).

En consecuencia, para consolidar una pedagogía de la reconciliación y la paz Colombia requiere no solo instituciones educativas y maestros que distingan lo que es la reconciliación y las competencias ciudadanas, que incluye como manifestación de ciudadanía. También se necesita reflexionar sobre las prácticas de aula y transformarlas cuando sea conveniente.

En este sentido, la propuesta del programa "Ciudadanía desde el aula", ofrece un conjunto de orientaciones y estrategias que podrían ser aprovechadas por los docentes del país, entre ellas la estrategia "Conversar es nuestro cuento", enfocada en la conversación, como manifestación de ciudadanía que emerge de la lectura de relatos sobre situaciones cotidianas (Barragán et al., 2018; Sánchez et al., 2018).

En estos últimos párrafos, se hace referencia a alternativas pedagógicas centradas en el potencial que ofrecen los relatos. En especial, en procesos de lectura, escritura y oralidad.

Al hablar de lectura conviene ampliar aquella noción basada en la eficiencia del lector para encontrar en un texto las respuestas que otro ha previsto. Larrosa (2003) propone entender la lectura esencialmente como una experiencia de búsqueda y construcción de sentido.

Leer no se refiere exclusivamente a la palabra escrita. Escuchar el testimonio de una víctima es otra forma de leer relatos que puede realizarse en el aula sin la presencia física del narrador gracias a las TIC; también, está la alternativa de leer textos impresos en voz alta. La lectura de un relato en voz alta tiene un poder inmenso y para algunos se trata de la actividad de lectura más importante en la infancia (Trelease, 2005).

Obviamente no se trata tan solo de la técnica o el medio, también se requiere atención en cuanto a los relatos en sí mismos. Para desarrollar las competencias necesarias para la reconciliación es indispensable romper el aislamiento que suele producirse en los relatos propios o en los predominantes. Es más difícil, por ejemplo, educar para la reconciliación cuando se promocionan (en películas, telenovelas, series, etc.) con tanta insistencia relatos que exaltan el uso de la fuerza y la violencia para derrotar al mal.

En el caso de los relatos testimoniales, los que se basan en hechos reales, conviene que sean leídos y escuchados la mayor variedad posible y que sean vistos desde diferentes aristas. Un ejemplo explícito lo constituyen los diversos documentos que han sido elaborados con minucia y rigor por parte del Centro de Memoria Histórica. Se trata, como ya se explicó, de propiciar una memoria que no se extingue en la repetición de hechos sino que crece a partir de la interpretación que sujetos y comunidades realizan.

Por otra parte, cuando se trate de relatos de ficción es necesario favorecer la publicación y circulación de aquellos que muestren la reconciliación como una alternativa favorable que haga contrapeso a los relatos que exaltan al héroe sometiendo al villano y haciéndole pagar sus faltas. Existen ya varias alternativas publicadas. Por ejemplo, García-Castellano (2016) realiza un compendio de cuentos populares de diferentes regiones y culturas a través de los cuales se evidencian tramas y desenlaces que hacen posibles la reconciliación y el perdón, sin eximir de su responsabilidad a los causantes de daño.

Tal vez sobre decir que las fábulas, con sus ínsitas moralejas, pueden tornarse desfavorables para una pedagogía de la reconciliación porque tienden a imponer una interpretación, que suele estar inclinada hacia la retaliación y el castigo. Cuando se usen fábulas en el aula sería pertinente proponer la reescritura de las mismas buscando nuevas soluciones a los conflictos que ellas presentan, enfrentarse a la moraleja. Por supuesto, vigilando siempre que la intervención pedagógica no caiga en otros adoctrinamientos.

Un ejemplo de cómo los relatos pueden escribirse desde diversas perspectivas es la célebre obra Voces en el parque (Brown, 2000), en la cual cuatro personajes narran la misma historia, con sorprendentes diferencias. Esta posibilidad de escritura y reescritura es sumamente valiosa en una pedagogía para la reconciliación. Un docente podría, por 
ejemplo, proponerles a sus estudiantes escribir el relato de un asalto a un supermercado desde diferentes perspectivas. Unos lo escribirían con el empleado encargado de la caja como narrador. Otros, lo narrarían asumiendo la voz de un asaltante. Algunos podrían escribir la versión de una madre embarazada que estaba en ese momento comprando el mercado para llevar a casa. También sería excelente que hubiera quienes escribieran la historia en la voz de un policía y en la de un testigo externo que vio los hechos a través de los mostradores del supermercado.

Este ejercicio de escritura se complementaría posteriormente con actividades de lectura que les permitieran a todos los estudiantes conocer las diferentes versiones del mismo relato, que serían preámbulo de sesiones de conversación que permitirían escuchar las impresiones causadas por lo escrito.

Conversar sobre relatos es una alternativa que exige abrir las puertas del discurso para que confluyan saberes diversos y perspectivas diferentes. Se espera que el docente vele por la inclusión de esta variedad, incluso cuando él mismo no esté de acuerdo con lo que algunos estudiantes expresen. Herrera y Chahín (2007) afirman que conversar es diferente a convencer. Así llaman la atención sobre aquella postura pedagógica que solo integra la voz del estudiante en la medida en que confirma los planteamientos del docente.

Sánchez (2018) presenta algunas características esperables de la conversación en el aula de clase, como resultado de uno de los proyectos de investigación del programa "Ciudadanía desde el aula". Entre ellas, aparecen la expresión asertiva y la escucha activa y positiva, competencias ciudadanas que entran en funcionamiento cuando se conversa en el aula con una adecuada intervención pedagógica.

Podrían presentarse muchas alternativas didácticas para propiciar la reconciliación, pero no es propósito de este texto ofrecer un menú de opciones sino proponer, en síntesis, el compromiso del docente y la escuela en pro de una educación que favorezca la reconciliación en un país como Colombia. El lenguaje sin duda será componente esencial, y los relatos (reales y ficticios) una materia prima sumamente útil en procesos que integren lectura, escritura y oralidad para favorecer competencias ciudadanas asociadas a la reconciliación, como manifestación de ciudadanía.

\section{Referencias}

Arias, A. (2010). La resiliencia en procesos de cuidado de la salud. San Gil, Colombia: Unisangil.

Barragán, F. y Arias, A. (2018). Enfoque pedagógico. En F. Barragán, A. Arias y L. Barragán, Ciudadanía desde el aula. Volumen I: orientaciones didácticas (pp. 9-24). San Gil, Colombia: Unisangil.

Barragán, F., Arias, A. y Barragán, L. (2018). Ciudadanía desde el Aula. Volumen II: estrategias didácticas. San Gil, Colombia: Unisangil.

Bocanegra, J., González, A. y Olaya, L. (2016). Una estrategia para la apropiación de las TIC en la reconciliación de las víctimas del conflicto armado colombiano. Trilogía, 8(14), 53-63. DOI: https://doi.org/10.22430/21457778.416

Brown, A. (2000). Voces en el parque. México D. F.: Fondo de Cultura Económica.

Bueno, M. (2006). La reconciliación como un proceso socio-político. Aproximaciones teóricas. Reflexión Política, 15, 64-78.

Camps, V. (2011). El gobierno de las emociones. Barcelona: Herder.

Chaux, E. (2012). Educación, convivencia y agresión escolar. Bogotá: Taurus. DOI: https://doi. org/10.7440/2012.62

Cortés, A., Torres, A., López-López, W., Pérez, C. y Pineda-Marín, C. (2016). Comprensiones sobre el perdón y la reconciliación en el contexto del conflicto armado colombiano. Psychosocial Intervention, 25(1), 19-25. DOI: https://doi.org/10.1016/j.psi.2015.09.004

Cyrulnik, B. (2005). El amor que nos cura. Barcelona: Gedisa.

Cyrulnik, B. (2009). Autobiografía de un espantapájaros. Barcelona: Gedisa.

Epston, D., White, M. y Murray, K. (1996). Una propuesta para reescribir la terapia. En S. McNamee y K. Gergen (comp.), La terapia como construcción social (pp. 121-144). Barcelona: Paidós. 
Fernández, C. (1997). Figuraciones de la memoria en la autobiografía. En J. Ruiz (comp.), Claves de la memoria (pp. 121-151). Madrid: Trotta.

Fundación para la Reconciliación (s. f.). Sobre la propuesta ES.PE.RE. Bogotá.

García-Castellano, A. (2016). Los cuentos populares en los procesos de perdón y reconciliación. Moralia, 39(152), 387-403.

Herrera, G. y Chahín, I. (2007). La fiesta de la conversación. Bilbao: Edex.

Hueso, V. (2000). Johan Galtung. La transformación de los conflictos por medios pacíficos. Cuadernos de estrategia, 111, 125-159. Recuperado de https://dialnet.unirioja.es/servlet/ articulo?codigo $=595158$

Larrosa, J. (2003). La experiencia de la lectura. México D. F.: Fondo de Cultura Económica.

López, E. (2013). Perdonar sí, olvidar no. Una aproximación a la reconciliación en Colombia desde los sentimientos morales. Universitas Philosophica, 30(61), 85-96.
Ruiz-Vargas, J. (1997). ¿Cómo funciona la memoria? El recuerdo, el olvido y otras claves psicológicas. En J. Ruiz (comp.), Claves de la memoria (pp. 121-151). Madrid: Trotta.

Sánchez, S. (2018). Conversar es nuestro cuento. En S. Sánchez, M. Gómez, R. Rodríguez, L. Barragán, S. Neira y F. Barragán, Ciudadanía desde el aula, Volumen II: estrategias didácticas (pp. 5-20). San Gil, Colombia: Unisangil.

Sánchez, S., Gómez, M., Rodríguez, R., Barragán, F., Neira, S. y Barragán, L. (2018). Ciudadanía desde el aula. Volumen I: orientaciones didácticas. San Gil, Colombia: Unisangil.

Shnabel, N. y Nadler, A. (2008). A needs-based model of reconciliation: Satisfying the differential emotional needs of victim and perpetrator as a key to promoting reconciliation. Journal of Personality and Social Psychology, 94(1), 116-132. DOI: https://doi. org/10.1037/0022-3514.94.1.116

Toro, B. y Tallone, A. (2011). Educación, valores y ciudadanía. Madrid: Organización de Estamos Iberoamericanos y Fundación SM. Recuperado de http://www.oei.es/historico/publicaciones/ detalle_publicacion.php?id=7

Trelease, J. (2005). Manual de la lectura en voz alta. Bogotá: Fundalectura.

Ugarriza, J. (2013). La dimensión política del postconflicto: discusiones conceptuales y avances empíricos. Colombia Internacional, 77, 141-176. DOI: https://doi.org/10.7440/ colombiaint77.2013.06

Unidad para la Atención y Reparación Integral a las Víctimas (s. f.). Convivencia, Reconciliación y Paz. Bogotá. research agenda. Journal of Business Ethics,
109(3), 275-287. https://doi.org/10.1007/ s10551-011-1125-1

Observatorio para la Paz (s. f.). Reconciliación.

Palanski, M. (2012). Forgiveness and reconciliation in the workplace: A multi-level perspective and research agenda. Journal of Business Ethics,
109(3), 275-287. https://doi.org/10.1007/ danas en Colombia? Al tablero, 27. Recuperado de https://www.mineducacion.gov.co/1621/ article-87299.html
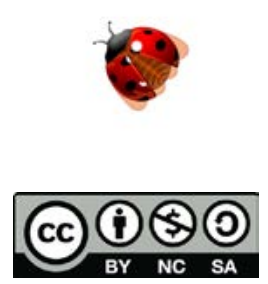

Esta obra está bajo licencia Creative Commons Atribución-NoComercial-Compartirlgual 4.0 Internacional https://creativecommons.org/licenses/by-nc-sa/4.0/deed.es ISSN 1657-9089 • Vol 18, No 1 (enero-junio 2019). pp. 95-104 